\title{
Familia "entre pares". Relaciones de solidaridad y vínculos de fraternidad entre travestis y transexuales de la Argentina contemporánea.
}

\author{
Family "between peers". Solidarity relations and bonds of \\ fraternity between transvestites and transsexuals of \\ contemporany Argentina.
}

Mariana Álvarez Broz*

\section{Resumen:}

Este artículo tiene por objeto dar cuenta de algunos aspectos de las trayectorias biográficas de travestis y transexuales vinculadas a la prostitución en la argentina contemporánea. Entre esos aspectos se focalizará en los problemas que se generan y las consecuencias sociales que acarrea para las travestis y las transexuales asumir su identidad de género en el seno familiar. Asimismo, nos interesa dar cuenta cómo el proceso de subjetivación trans las conduce a abandonar el hogar familiar a una edad muy temprana y a establecer nuevos vínculos sociales y afectivos con otras travestis y transexuales, con quienes conformarán su nueva familia, basada en relaciones de solidaridad y vínculos fraternos.

Palabras Clave: travestis-transexuales-socializacion-solidaridad-familia

\begin{abstract}
:
This article takes into account for some aspects of the biographical trajectories of transvestites and transsexuals linked to prostitution in contemporary Argentina. I will focus on the problems that are generated and the social consequences for transvestites and transsexuals to assume their gender identity into de family home. Likewise, I am interested in explaining how the process of trans subjectivation leads them to leave the

\footnotetext{
*. Doctora en Sociología (IDAES-UNSAM). Magister en Sociología de la Cultura y Análisis Cultural (IDAESUNSAM). Licenciada en Ciencias de la Comunicación (FSOC-UBA). Docente e investigadora (IDAES-UNSAM y FSOC-UBA). Co-coordinadora del Programa de Estudios sobre Sexualidades, Géneros y Violencias (IDAESUNSAM).
} 
Revista Punto Género N. 9. junio de 2018

ISSN 0719-0417 / $128-146$

family home at a very early age and to establish new social and affective ties with other transvestites and transsexuals, with whom they will form their new family, based on relationships of reciprocity and Fraternal bonds.

Keywords: transvestite-transsexual-socialization-solidarity-family

Fecha de recepción: 6 de junio 2017

Fecha de aprobación: 30 de mayo 2018

\section{Introducción}

El presente artículo surge de la investigación que dio lugar a mi tesis doctoral ${ }^{1}$ sobre las formas, los mecanismos y las relaciones de (des)igualdad que atraviesan a las personas trans ${ }^{2}$ en la Argentina contemporánea. En esta oportunidad, y sobre la base del trabajo de campo iniciado en marzo de 2013, me propongo dar cuenta de algunos aspectos de las trayectorias de vida de las personas que se autoidentifican como travestis y transexuales ${ }^{3}$ vinculadas a la prostitución.

El propósito de este artículo es mostrar cómo los avatares del proceso de subjetivación trans lleva a travestis y transexuales (TyT $)^{4}$ a desafiliarse -más temprano que tarde- de sus familias de origen, y a transitar un camino sinuoso que las llevará a encontrarse con otras trans y a iniciar una nueva vida juntas. Esos vínculos sociales que las travestis y las transexuales establecen con otras trans resultaran fundamentales y decisivos a lo largo de sus recorridos biográficos y, especialmente, en su devenir trans, al punto de conformar lo que di en llamar una familia "entre pares".

En este sentido, este trabajo pone de relieve cómo el hecho de asumir la identidad trans no sólo afecta y trastoca la vida cotidiana de las travestis y transexuales sino también propicia nuevas formas de relacionamiento basadas en lazos de solidaridad, mecanismos de reciprocidad y vínculos fraternos.

Este trabajo se enmarca en el cruce particular que se produce entre el campo de estudios de las desigualdades sociales en diálogo con los estudios sociales de las sexualidades y teorías de (trans)género/queer. En esa articulación, donde las perspectivas clásicas y contemporáneas de los estudios sobre desigualdad se

\footnotetext{
1 Doctorado en Sociología, Instituto de Altos Estudios Sociales de la Universidad Nacional de San Martín (IDAES-UNSAM), de Argentina.

2 Entiendo por personas trans a aquellas que, en términos generales, producen una ruptura de la norma sexo-genérica no identificándose con el sexo asignado al momento de nacimiento y/o con el binario femenino-masculino.

${ }^{3}$ Utilizo las categorías travesti y transexual porque así se han identificado las informantes que participaron en esta investigación. En particular, sostengo denominación travesti en tanto remite a una trayectoria social, cultural y política específica en América Latina y Argentina, y en tanto es reivindicada con orgullo como posición política como una forma de resistencia a la corporalidad binaria y a la dicotomía sexo-genérica (Berkins, 2003).

${ }^{4}$ De acá en más utilizaré la abreviatura "TyT" para referirme a travestis y transexuales.
} 
intersectan con las experiencias subjetivas móviles, fluidas y contingentes trasvasando las miradas disciplinarias, y los estudios de las sexualidades disidentes y las identidades trans incorporan el lente analítico que les permite ver las asimetrías sociales en las que están insertas, se ubica esta investigación y es desde donde sitúo y elaboro mis reflexiones.

En lo que concierne al abordaje teórico-metodológico, encaré este trabajo a partir de la noción de trayectoria en tanto ofrece elementos que contribuyen a una acabada comprensión del entramado del sujeto con lo social (Bourdieu, 1977). En tanto, el estudio de las trayectorias vitales permite obtener informaciones biográficas y además posibilita una contextualización de los procesos, es decir, la vinculación entre la biografía individual y las características estructurales de la situación histórica vivida (Bertaux, 1999).

Es en las trayectorias donde se ponen de manifiesto las disposiciones y las prácticas de los actores. Y si bien existe una correlación entre esas prácticas y su origen social (como mostraré en este artículo, por ejemplo, entre las trayectorias de las travestis y las transexuales y su vinculación con la práctica de la prostitución) no debe soslayarse la capacidad de agencia de cada una de ellas a lo largo de toda la experiencia vital. Puesto que en cada trayectoria se presentan una cantidad de factores que cada TyT toma en consideración o desestima -consciente o inconscientemente- en su accionar.

Para abordar las trayectorias de vida de las travestis y transexuales, adopté un enfoque biográfico $0^{5}$ que me permitiera poner en diálogo de manera dialéctica la historia individual y la historia social, a partir del estudio de las experiencias de vida de las personas trans.

Trabajé, específicamente, con el método conocido como "relato de vida" (life stories) en su variante interpretativa comprensiva (Bertaux, 1981) con el propósito de identificar y describir los "índices", entendidos como aquellos aspectos que son reconocidos tanto por las autoras del relato como por el investigador como hechos que han marcado, sociológicamente hablando, la experiencia de vida de estas personas.

Me interesó esta perspectiva en tanto supone un proceso activo por parte del sujeto quien interpreta su vida seleccionando y organizando determinados acontecimientos, anécdotas, momentos de transición, escenarios, personas involucradas, explicaciones y justificaciones ex post facto, con los cuales va configurando una unidad de sentido. Estas "formas de relatar los acontecimientos tiene espesor sociológico en sí mismo, ya que puede apreciarse con qué elementos se arma la trama" (Meccia, 2011: 39).

Pensar los itinerarios biográficos supuso prestar especial atención a la dimensión temporal, esto es, pues, a los cambios (históricos o personales) por su incidencia y repercusión en las trayectorias vitales. En este sentido, los relatos de vida resultan propicios para dar cuenta de ese "punto de viraje" -también llamado "punto de inflexión" o "carrefour"- identificados por el sujeto, a partir del cual su biografía adopta un rumbo distinto o inicia una nueva etapa. Pero el interés no fue sólo identificar o describir esos momentos clave, sino más bien llegar a comprender qué llevó a esa persona a tomar

\footnotetext{
${ }^{5}$ El método biográfico constituye una manera -entre otras- de hacer sociología desde principios del siglo XX. Fue en el marco de la Escuela de Chicago, y a partir de la década del '20, que proliferaron los estudios de los relatos y las historias de vida y los estudios de caso en obras pioneras como las de Thomas y Znaniecki (El campesinado polaco en Europa y América, publicada en 1918-1920) y, más tarde, el trabajo de Oscar Lewis (Los hijos de Sánchez, en torno de la pobreza, publicada en 1964). Después de la Segunda Guerra mundial, se impuso la hegemonía de la sociología norteamericana -con sus pilares en el método de encuestas y el funcionalismo parsoniano- sobre todas las otras formas de observación y de teorización (Bertaux, 1981).
} 
ese camino y no otro, a dar ese cambio, en ese momento particular y en esa situación social específica (Kornblit, 2007: 23).

En ese marco, me ocupé tanto de la dimensión "socio-estructural" como de la "sociosimbólica" (Bertaux, 2005); es así como al tiempo que me centré en la escucha atenta de los relatos y su posterior sistematización y organización, relevé datos en torno a sus condiciones socio-demográficas (nivel de estudios alcanzado, ocupación y fuente de ingresos, cobertura médica, etc.) en función del material estadístico disponible, al cual me referiré en párrafos ulteriores.

En lo que hace a las técnicas de recolección de la información, las narrativas biográficas fueron obtenidas a través de la realización de entrevistas en profundidad con un tipo de contacto personal "cara a cara" y de modalidad semi-estructurada y, en ocasiones, no estructuradas (o conocidas también como entrevistas abiertas), generalmente como complemento de la observación en campo, privilegiando el continuum de libertad concedido a la entrevistada (Marradi, 2012). Éstas tuvieron como propósito no sólo la obtención de información referida a la sucesión de acontecimientos vividos sino también a la verbalización de una apropiación individual de la vida colectiva (Alonso, 1998).

En cuanto a la muestra, llevé adelante veinte entrevistas a travestis y transexuales femeninas vinculadas a la prostitución (ya sea en su pasado o en la actualidad), de entre 25 y 60 años, quienes al momento del trabajo de campo habitaban el área Metropolitana. ${ }^{6}$ Las entrevistas fueron realizadas en su totalidad a través de la técnica conocida como bola de nieve. La decisión y elección de esta técnica responde a la importancia -y la necesidad- de llegar a las personas trans mediante otra persona trans, más allá de que fuera amiga/o, conocida/o, o que sólo lo/a hubiera visto/a una vez en la vida. En ese sentido, la puerta de entrada a las entrevistas fue, sin duda, la condición trans de la persona "en común". 7

Las dimensiones abordadas en las entrevistas fueron las que se detallaran a continuación:

\begin{tabular}{|c|c|}
\hline Planos & Travestis \\
& y Transexuales(TyT) \\
\hline
\end{tabular}

\footnotetext{
${ }^{6}$ Es dable esta aclaración porque, como sabemos, las trayectorias vitales de las travestis y transexuales están atravesadas por la migración interna -de una provincia a otra y, en especial, de las provincias a la Ciudad de Buenos Aires- y, en menor medida, a otros países.

${ }^{7}$ Se contactó a la mayoría de las personas a través del número de teléfono o e-mail que me brindaba algún informante. A otras conocí personalmente como resultado de una presentación de otras travesti o transexual- a partir de la cual quedamos en contacto. La mayoría de estas personas se interesó por conocer para qué era la entrevista, y algunas otras, cuál era el tema de la investigación. En todos los casos, les pregunté donde preferían establecer el encuentro. En general travestis y transexuales manifestaron sentirse más cómodas en sus casas particulares (algunas prefirieron ir a un bar porque convivían con otra persona). Con varias de ellas me encontré -y hasta acordé encuentros informales- en otros ámbitos por fuera de la situación de la entrevista, como en actividades artísticas, charlas-debate sobre temas trans, marchas, presentaciones de libros, en la zona roja de Palermo o Constitución, en fiestas, recitales, jornadas académicas, por mencionar algunos eventos. En todos los casos grabé -previa autorización de las personas- las entrevistas, y decidí no tomar ningún tipo de notas para no perder el contacto visual con las entrevistadas y generar un ambiente de conversación relajada e informal. La gran mayoría de las entrevistas (el $95 \%$ aproximadamente) fueron realizadas durante los años 2013 y 2014, sólo algunas pocas durante el 2015. Fueron entrevistas de dos horas de duración promedio (algunas hora y media, otras tres). En casi todos los casos, les envié, luego, la grabación textual de la entrevista. Todas me indicaron cómo querían ser nombradas en el manuscrito producto del trabajo de investigación.
} 


\begin{tabular}{|c|c|}
\hline Familiar & $\begin{array}{c}\text { Abandono temprano de la casa. Familia "ampliada" } \\
\text { con TyT. }\end{array}$ \\
\hline Educativo & Abandono de la escuela primaria. \\
\hline Laboral & La prostitución como medio de subsistencia. \\
\hline Salud & $\begin{array}{c}\text { Acceso deficitario o nulo. Prácticas de intervención } \\
\text { corporal "colectivas". }\end{array}$ \\
\hline Sociabilidad & $\begin{array}{c}\text { La pensión o la zona de prostitución como ámbitos } \\
\text { privilegiados de conformación de redes de apoyo y } \\
\text { solidaridad con otras TyT. }\end{array}$ \\
\hline
\end{tabular}

Es dable aclarar que el esquema presentado previamente adquiere ciertos matices en las entrevistas realizadas, sin embargo existe una suerte de modelización del relato (Plummer, 1994) a partir de ciertas recurrencias significativas que relevé a lo largo de los relatos de vida de TyT vinculadas a la prostitución.

\section{Datos de contexto}

Hacia fines de los años '90 y principios de los años 2000 se han registrado cambios importantes en torno a la regulación político-estatal de la sexualidad y el género en un sentido más liberal e igualitario en América Latina (Pecheny y De la Dehesa, 2011). En el caso de la Argentina, se dio un proceso de sensibilización en torno al reconocimiento de los derechos sexuales y a la diversidad de las identidades sexo-genéricas que se correspondió con su ingreso a la agenda social y política, configurando un nuevo escenario en lo relativo al vínculo entre ciudadanía y derechos socio-sexuales.

Eso no significa que desde el Estado se haya adoptado una postura uniforme en torno a las identidades trans, al contrario, se produjeron desde las distintas agencias estatales discursos públicos en conflicto, en particular, alrededor de los tratamientos médicos de construcción corporal trans, y en lo relativo a los tratamientos hormonales y quirúrgicos (Farji Neer, 2016).

En ese marco, también los debates parlamentarios acogieron y le otorgaron un marco legal a los reclamos históricos de distintos colectivos del movimiento feminista y de la diversidad sexual, logrando avances significativos en la política sexual, reproductiva y de géneros (Petracci y Pecheny, 2006). ${ }^{8}$

La ley de Identidad de Género sancionada en Argentina en el año $2012^{9}$ resultó el reconocimiento a la lucha de la comunidad trans llevada adelante durante décadas en pos de lograr el respeto, la dignidad y la igualdad de personas travestis, transexuales y transgéneros. En materia legislativa es considerada una ley pionera en la región latinoamericana y de vanguardia a nivel internacional por concebir la identidad en el marco de los Derechos Humanos y por ser la única ley de identidad de género en el mundo que no patologiza ${ }^{10}$ la condición trans.

\footnotetext{
8 En ese marco, se sancionaron algunas leyes significativas: la ley $N^{\circ} 25.673$ (Año 2003) Programa Nacional de Salud Sexual y Procreación Responsable; la ley № 26.485 (Año 2009) Protección integral para prevenir, sancionar y erradicar la violencia contra las mujeres en los ámbitos en que desarrollen sus relaciones interpersonales; la ley № 26.628 (Año 2010) de Matrimonio Igualitario, por mencionar algunas.

9 Ley № 26.743 , conocida como Ley de Identidad de Género, fue sancionada el 10 de mayo de 2012 en la Argentina.

10 Se conoce como patologización al etiquetamiento de determinadas conductas 0 comportamientos como enfermedad o anormalidad.
} 
En este sentido, la ley suscribe que toda persona tiene derecho "al reconocimiento de su identidad de género, al libre desarrollo de su persona conforme a su identidad de género, y a ser tratada e identificada de ese modo" (Art. $1^{\circ}$ ). Asimismo, "deberá respetarse la identidad de género adoptada por las personas, en especial por niños, niñas y adolescentes que utilicen un nombre de pila distinto al consignado en su documento nacional de identidad" (Art $12^{\circ}$ ). Toda persona "podrá solicitar la rectificación registral del sexo, y el cambio de nombre de pila e imagen cuando no coincidan con su identidad de género autopercibida" (Art. $3^{\circ}$ ). También, "aquellas personas mayores de dieciocho años de edad podrán (...) a fin de garantizar el goce de su salud integral, acceder a intervenciones quirúrgicas totales o parciales y/o tratamientos integrales hormonales para adecuar su cuerpo, incluida su genitalidad, a su identidad de género autopercibida, sin necesidad de requerir autorización judicial o administrativa" (Art. $11^{\circ}$ ). Sobre este último punto cabe mencionar que recién en mayo de 2015 , mediante el Decreto № 203/2015 ${ }^{11}$ se reglamentó el artículo 11 de la Ley de Identidad de Género, que garantiza que las intervenciones quirúrgicas parciales o totales o los tratamientos hormonales para adecuar el cuerpo a la identidad autopercibida serán incluidas en el Programa Médico Obligatorio (PMO) tanto en el ámbito público como privado, lo que significa que las prácticas de modificación del cuerpo trans son reconocidas dentro del ámbito de la salud integral de una persona y no como un "cuestión estética".

En un contexto de "controversias sobre la desigualdad" (Kessler, 2014) en Argentina de los últimos años se produjo una suerte de ciudadanía sexual (Pecheny, 2001) - es decir de reconocimiento de los derechos sexo-genéricos de las personas que integran la comunidad LGTB - cuyo marco propició ciertos avances en materia de derechos para las personas trans.

En paralelo, y en el marco de este nuevo escenario socio-político se generó un diálogo productivo -aunque por momentos tenso- entre el activismo y la academia que produjo aportes significativos al estudio de las condiciones de vida del movimiento de la diversidad sexual en general y de la comunidad trans en particular, aunque en menor medida. ${ }^{12}$

Los estudios sobre la comunidad trans adoptaron, en su mayoría, un enfoque cuantitativo y arrojaron resultados parciales y acotados en algunas provincias (Tucumán, Córdoba, Salta, Mendoza, Neuquén) o distritos de gran concentración poblacional (la Ciudad de Buenos Aires, Mar del Plata o el partido de La Matanza de la Provincia de Buenos Aires, por dar algunos ejemplos). La gran mayoría de estos estudios se realizaron en base a encuestas que llevaron adelante las propias organizaciones trans en conjunto con investigadores, organismos del Estado, centrándose en aspectos socio demográficos y en las condiciones de vida (Defensoría de la Ciudad de Buenos Aires, 1999; Berkins y Fernández, 2005; Jones, Libson y Hiller, 2006; INDEC e INADI, 2012), experiencias de atención médica, cuidados del cuerpo y VIH-sida (Ministerio de Salud de la Ciudad, 2005; Ministerio de Salud de la Nación, 2010;

11 El Decreto № 903/2015 (B.O. 29-05-2015) aprueba la reglamentación del artículo 11 de la Ley № 26.743 sobre el Derecho a la Identidad de Género.

12 Desde principios de los años 2000, los estudios sobre sexualidades han venido creciendo como campo académico. En ese marco, se ha producido una diversificación y un crecimiento de abordajes que combinan investigaciones empíricas, lineamientos teóricos y miradas críticas sobre identidades y sexualidades disidentes. Esta proliferación puede apreciarse en la publicación de libros y artículos académicos, en la organización de jornadas y congresos, como así también en la creación de maestrías y diplomaturas, formación de grupos y áreas de investigación, en la incorporación de asignaturas transversales como específicas en las carreras en distintas universidades de la Argentina. 
Fundación Huésped, 2012) estigma y discriminación (INDEC e INADI, 2012; Fundación Huésped, 2012).

A pesar de los avances en materia de derechos sexuales, algunos de los resultados más destacados que arrojan estos estudios muestran que la principal causa de muerte en la comunidad trans femenina es el virus del VIH/sida, cuya prevalencia entre 2001 y 2009 fue del 34\% en travestis y transexuales (Boletín Epidemiológico de $\mathrm{VIH} / \mathrm{sida}$, 2009). Le siguen los asesinatos por razones transfóbicas (conocidos también como "crímenes de odio") y por violencia policial, las complicaciones derivadas por inyección "casera" de siliconas. Otras causas de muerte son los suicidios, la diabetes, la sobredosis de drogas, las muertes vinculadas a la pobreza y la marginalidad (como consecuencia de la negativa a concurrir a un hospital público por temor a ser estigmatizada y maltratada) el abandono de persona en instituciones médicas, el deterioro de la salud por enfermedades renales o hepáticas a causa de la ingesta sostenida de hormonas para modificar los cuerpos (Berkins y Fernández, 2005). Por otro lado, la prostitución se presenta como la principal fuente de ingresos de travestis y transexuales (79\% en Berkins, 2007; 73,2 \% según el INDEC e INADI, 2012), mostrando, además, un acceso muy precario a "derechos básicos" como la educación, la salud, el trabajo y la vivienda (Berkins y Fernández, 2005)

Estos estudios ponen en evidencia, tal como señalaba Kessler (2014), que si bien podemos hablar de una mayor igualdad en ciertos aspectos -en este caso relativa al plano del reconocimiento de los derechos sexo-genéricos, por ejemplo-, esta mejora convive con la perdurabilidad de la desigualdad en algunas esferas clásicas como el acceso a la salud, el acceso al trabajo, por mencionar algunas. Estas tensiones, sin duda, reactualizan el debate en torno a la relación entre reconocimiento y redistribución (Fraser, 1995), y en lo personal esto me llevó a analizar cómo se trama la dimensión material con la simbólico-cultural en la vida cotidiana de las personas trans.

\section{Desafililiadas}

Es durante la primera infancia que las travestis y las transexuales comienzan a construir sus identidades a través del uso de la indumentaria, los gestos, la forma de peinarse, los modales o la preferencia por ciertas actividades. Sus prácticas infantiles -más o menos clandestinas- dan cuenta de su adscripción temprana al travestismo o a la transexualidad aunque este no forme parte todavía del lenguaje con el que se nombran -dada su corta edad-; lo hacen, pues, manifestando el deseo de portar atributos femeninos (Fernández, 2004).

Esta forma de presentarse ante los demás, y el encuentro frustrante con la mirada reprobatoria de su familia es el primer síntoma de incomodidad que registran en su entorno social, y el primer indicio de su indeseable diferencia (Goffman, 2012 [1963]).

Margarita, quien se identifica como travesti, tiene cincuenta y seis años y se asume como una sobreviviente. ${ }^{13}$ Se fue de su casa a los diez años, debido a las situaciones de maltrato y agresión en el seno de su familia. Así lo recuerda:

${ }^{13}$ De acuerdo a los datos disponibles, hasta entrados los años 2000, la expectativa de vida de una travesti o transexual -sobre todo en situación de prostitución- era de 35 años (Berkins y Fernández, 2005). 
Cuando era muy chica, y a causa de mis mariconeadas, mi padre me encerraba en el lavadero del fondo de la casa, y hasta a veces me ataba como penitencia. Mi hermano [mayor] le hacía la segunda y mi mamá veía eso y lo toleraba. Él [su padre] me decía que tenía que arrepentirme y prometer que nunca más volvería a hacerlo. Y como yo no me arrepentía, me dejaban horas atada ahí (Entrevista de la autora a Margarita, Cdad. de Buenos Aires, 26/04/2013).

Cuando le pregunté a qué tipo de mariconeadas se refería, ella me contó que desde pequeña, cuando nadie la veía, entraba al cuarto de sus padres y sacaba del ropero de su mamá algunas prendas femeninas para jugar. Los fines de semana, después del almuerzo, cuando sus padres dormían la siesta, se escondía en su cuarto y se probaba frente al espejo blusas, vestidos y polleras. Sentía mucho placer al verse así y lucir, aunque sea por un rato y sólo para ella, una imagen femenina. También disfrutaba mucho de aquellos momentos donde se encerraba en el baño y se colocaba el polvo de maquillaje y la máscara de pestañas de su madre. Como no tenía práctica y le llevaba más tiempo limpiarse bien la cara para que no quedaran rastros, se maquillaba sólo los días de semana mientras su madre salía de compras con los hermanos más chicos, y aprovechando que su padre no regresaba a la casa hasta la hora de la cena. Las veces que fue sorprendida por su hermano mayor, éste se lo contó a sus padres y como consecuencia, recibió varias reprimendas y hasta fuertes golpizas. Pero como sus comportamientos-repudiados por su familia-no sólo no cedían sino que eran cada vez más evidentes y pronunciados, su padre la echó de la casa a sus diez años por sus prácticas maricas, y le pidió que nunca más volviera porque manchaba el nombre y el honor de la familia. Y así fue como nunca más volvió a saber de ellos.

En relación a otros niños y a otras niñas, estas primeras experiencias de vida están atravesadas por la contradicción y el conflicto (Fernández, 2004), debido al desajuste que se produce entre su deseo y las expectativas socioculturales que dictan las conductas apropiadas para una mujer o un varón. Este desacople que se manifiesta a muy temprana edad desencadena una variedad de conflictos, en principio, en el ámbito familiar.

Al respecto, Rubin (1989) sostiene que las familias juegan un papel muy importante en la tarea de imponer la conformidad sexual. A través de ellas se ejerce la presión social dirigida a negar a las personas disidentes erótico-sexuales los recursos y las comodidades que ofrece y proporciona la familia, puesto que el sentido común establece que éstas no deben ser cómplices de este inconformismo, sino más bien deben bregar por desterrarlo a través del empleo de castigos y reprimendas, lo que va generando un ambiente familiar marcadamente expulsivo.

A diferencia de otros grupos sociales estigmatizados o discriminados (por causas étnicas, religiosas, nacionales) donde la familia funciona como un resguardo del entorno social que se presenta excluyente (Pecheny, 2001), en el caso de las TyT ésta se va tornando un espacio de hostigamiento y de agresión al punto de convertirse en la primera instancia de rechazo social que experimentan estas personas. Incluso hasta por sus madres que, de acuerdo a lo que muestran otras investigaciones, resulta esa figura incondicional (Kessler, 2004) que no abandona a sus hijos, que da todo por ellos, sin importar lo que hayan hecho. Esto las diferencia de otros grupos en situación de vulnerabilidad donde, por lo general, la familia es el lugar de cobijo que encuentran frente a situaciones externas adversas. 
Según muestran los estudios disponibles con enfoque cuantitativo ${ }^{14}$ existe una correlación entre la edad en que asumen su identidad de género y el momento en que abandonan sus hogares. Respecto de la edad en que se asumen como travestis o transexuales, más del $50 \%$ asumen su identidad de género durante la adolescencia entre los 14 y los 18 años, el 35\% antes de los 13 años, y el $15 \%$ restante después de los 18 años.

Esos años en los que se produce el desarraigo de sus familias constituye un momento de definición de roles y búsquedas identitarias en sus biografías. Además, en tanto estado de transición entre la niñez y la juventud, ese período torna particularmente vulnerable sus trayectorias de vida justamente porque una transición supone no un estado ni el siguiente sino más bien esa instancia liminal e incierta (Douglas, 2004) entre un momento y el otro. Este marco de situación da cuenta del contexto de desprotección y desamparo en el que transitan su proceso de crecimiento y desarrollo.

\title{
La nueva familia
}

Ante la falta de comprensión y contención de su entorno primario las TyT abandonan sus hogares y comienzan un camino a la deriva. Para aquellas que lo hacen a muy temprana edad -como es el caso de Margarita- la calle y los vínculos que allí mismo comienzan a armar pasan a ocupar un lugar central en sus vidas (Prieur, 1998). Durante ese itinerario construyen fuertes lazos sociales con sus pares, otras TyT. En ese transcurrir, van aprendiendo juntas a rebuscárselas en la calle con lo que se les va presentando y a sostenerse con lo que tienen a su alcance, sobre todo, con aquel saber hacer que le transmiten sus compañeras para su subsistencia. Así lo expresaba Margarita:

\begin{abstract}
Cuando me echaron [de la casa] a los diez años por mi condición de marica, me subí al tren desde Garín, terminé en Retiro y después aparecí en Constitución...y a partir de ahí viví en la calle y de la calle por mucho tiempo. Ahí [en la calle] conocí a Lucy, otra marica ${ }^{15}$, y fuimos como hermanas. Empezamos a abrir puertas de taxis, corríamos de la policía, caíamos de vez en cuando en institutos de menores hasta que nos soltaban. El [colectivero] del 60 ya nos conocía, y nos dejaba dormir en los asientos de atrás durante la noche, todo el recorrido, a veces ida y vuelta... fueron complicadísimos esos años... pero al menos nos tuvimos una a la otra, nos acompañamos en todo, las pasamos feas pero al menos estábamos juntas (Entrevista de la autora a Margarita, Cdad. de Buenos Aires, 26/04/2013).
\end{abstract}

\footnotetext{
${ }^{14}$ Las fuentes consultadas son: Informe preliminar sobre la situación de las travestis en la Ciudad de Buenos Aire, Defensoría del Pueblo de la Ciudad de Buenos Aires y Asociación de Lucha por la Identidad Travesti y Transexual (ALITT), 1999; Berkins, Lohana y Fernández, Josefina (2005) Coord. La gesta del nombre propio. Informe sobre la situación de la comunidad travesti en la Argentina, Ediciones Madres de Plaza de Mayo, Buenos Aires, Argentina; Berkins, Lohana (2007) Cumbia, copeteo y lágrimas. Informe nacional sobre la situación de las travestis, transexuales y transgénero, ALITT, Buenos Aires, Argentina; Primera encuesta sobre Población Trans: Travestis, transexuales, transgéneros y hombres trans. Informe técnico de la Prueba Piloto en el Municipio de La Matanza, Instituto Nacional de Estadísticas y Censos-Instituto Nacional contra la Discriminación, la Xenofobia y el Racismo, 2012; Arístegui, I., Vázquez, M., Dorigo, A. \& Lucas, M. (2012). Percepciones y experiencias sobre estigma y discriminación en poblaciones trans, HSH y usuarios de drogas. Buenos Aires: Fundación Huésped con colaboración de Red de personas viviendo con VIH de Mar del Plata.

${ }^{15}$ Marica es una categoría nativa de constante referencia en las conversaciones de las travestis. Alude a un conjunto de prácticas, comportamientos y saberes disponibles para las travestis, tanto para pensarse como para identificarse a sí mismas, como para referirse a otros homosexuales no identificados con travestis. Para ampliar información véase Cutuli (2013).
} 
En el desafío cotidiano de la sobrevivencia se va tramando una especie de comunión entre las TyT que, como ellas mismas dicen, las hermana ante la soledad, la desprotección y las acuciantes necesidades económicas con las que se encuentran en el camino del desarraigo. Expulsadas de aquellos ámbitos de socialización primaria y privadas de aquellos vínculos imprescindibles para el desarrollo psico-social y emotivo de la vida cotidiana, las TyT, unas con otras, van conformando una verdadera familia ampliada (Pollak, 1993).

Pero no todas son expulsadas -al menos explícitamente- de sus casas. Otras deciden por sí mismas abandonar el hogar familiar para evitar conflictos y poder expresar su género sin la mirada sancionatoria y estigmatizante de su entorno: familia, amigos y vecinos.

"A veces es la única que te queda", afirmó Daniela cuando le pregunté por qué se había ido tan joven de su hogar familiar. Ella nació en la ciudad de Córdoba pero vivió su temprana adolescencia en la provincia de Mendoza. ${ }^{16}$ Se mudó allí a los catorce años a la casa de una vecina de su barrio -que oficiaba de tía postiza- mediante una autorización firmada por sus padres. La situación en su casa era insostenible. Así que de uno u otro modo iba a terminar yéndose.

Ese primer desarraigo significó para ella un "escape", fue una sensación de liberación. Porque después de tantas recriminaciones por parte de su familia, irse lejos resultó esa "bocanada de aire" que necesitaba para poder asumir su identidad sin la sanción constante de los suyos: "Yo sabía que me tenía que ir, que lamentablemente era la única solución (...) no soportaba más el ambiente que se había generado en casa, tanto maltrato, tanta pelea, era un caos...". Y mudarse a Mendoza fue la opción que encontró para no quedar desde pequeña tan a la deriva.

Una vez allí, transitó esa búsqueda identitaria propia de un/a adolescente, pero sin saber bien de qué se trataba eso de "querer ser una chica" y que tanto conflicto había desatado en su familia. Esa tía postiza la acompañó desde su lugar: la contuvo en esos momentos en los que ella necesitó tener una familia al lado mientras experimentaba los primeros pasos de su transición hacia el género femenino. Hasta los dieciocho años estuvo "yendo y viniendo, como chico y como chica...". Buscándose, probando, descubriéndose.

Cuando Daniela cumplió los diecinueve años, decidió hacerse camino sola. Ahí mismo en Mendoza se mudó a una pensión -que le había recomendado una amiga- donde se alojaban TyT. El encuentro con otras travestis la ayudó a reconciliarse con la diferencia que portaba. Sintió mucha tranquilidad al saber que ella no era la única, que tenía historias en común con otras chicas, de desconcierto, de maltrato, de soledad, y de crecer con culpa por sentirse diferente a lo que se esperaba de ella. Y, también, a transitar el difícil camino que implica "hacerse sola" ante la necesidad de subsistencia. Así rememora el encuentro y la convivencia con sus pares:

La bautizamos "la pajarera". Había chicas entrando y saliendo todo el tiempo, las veinticuatro horas. Se vivía con las puertas de las habitaciones abiertas de par en par. Nos levantábamos después del mediodía, nos cocinábamos en grupo porque sólo había dos cocinas chiquitas para compartir entre todas- y nos pasábamos la tarde sentadas en las escaleras chusmeando. Ya pasadas las cuatro [de la tarde] empezaba la cola en el baño, todas haciendo fila con la toalla en la mano. Había tres baños grandes pero para todas no alcanzaba... porque a esa hora empezábamos todas a producirnos para estar divinas y salir a hacer la

${ }^{16}$ Córdoba y Mendoza son dos provincias de la República Argentina. 
calle [prostituirse] (...) No te digo que nos llevábamos todas bárbaro y que éramos todas amigas, pero al menos una ahí sentía que no estaba tan sola, que la falta de la familia dolía un poco menos...y de pronto si una noche no habías trabajado bien o te habías gastado la plata en remedios o te faltaba un mango para cubrir el alquiler de la pieza sabías que no te ibas a quedar tirada en la calle, porque siempre alguna te iba a bancar. Éramos como una familia... (Entrevista de la autora a Daniela, 12/07/2013, Avellaneda, Provincia de Buenos Aires, 32 años)

Al igual que en el relato de Margarita, observamos que para Daniela el encuentro con otras TyT constituyó, también, un hito fundamental en el curso de su vida. En primer lugar, por la fuerte identificación que se produce entre ellas, puesto que el hecho de tomar contacto con otra persona que posee su mismo estigma -una identidad sexogenérica desviada de la heteronorma- es lo suficientemente significativo como para advertir y tomar consciencia que existen otras iguales a ella y formar una familia. En segundo lugar, porque la calle, el hotel o la pensión se convierten en ámbitos de sociabilidad donde se establecen vínculos de fraternidad sumamente significativos para ellas.

Al igual que plantea Míguez (2010) sobre el barrio y la calle para el caso de los jóvenes de los sectores populares relacionados con hechos delictivos, es en la calle, el hotel y la pensión en tanto espacios privilegiados de sociabilidad donde las TyT irán conformando nuevos sistemas de valores, hábitos y actitudes que marcarán sus trayectorias de vida.

A diferencia de otras personas inmersas en un proceso constante de construcción de relaciones sociales en espacios como la escuela, la universidad, el trabajo, el vecindario, el club, etcétera, las TyT tienen un universo relacional limitado -debido a situaciones de discriminación y estigmatización- generándose así un trayecto de movilidad relacional centrípeta (Meccia, Metlika y Raffo, 2001) que las lleva, casi inevitablemente, a coincidir en el curso de sus vidas con otras compañeras de infortunio (Goffman, 2012) quienes intervendrán decididamente, como veremos más adelante, en sus itinerarios vinculados a la prostitución.

\section{Vivir como golondrinas}

Como hemos visto, el desarraigo familiar constituye una variable fundamental en sus trayectorias de vida. Muchas de ellas, no sólo abandonan sus hogares sino también migran hacia otras ciudades, provincias o países por diferentes motivos: algunas lo hacen en busca del anonimato que les permita dejar atrás su identidad masculina para comenzar su verdadera vida ${ }^{17}$; otras con el propósito de construir su feminidad en entornos menos hostiles (Berkins, 2007), y algunas otras con la ilusión de mejorar las condiciones materiales en las que viven.

La historia de Daniela ilumina alguno de estos aspectos. Ella siempre buscó estar alejada de esas miradas violentas que la condenaron desde pequeña. Eso la mantuvo inquieta. Vivió yendo y viniendo, mudándose de provincia, recorriendo pensiones, hoteles y casas de amigas. "Siempre alguna te recibe, te alquila una piecita, te presta una cama o simplemente te deja tirarte a dormir en el sillón del living. Así vivimos las travas, girando de lugar en lugar".

Anduvo por Formosa, La Rioja, Santiago del Estero, Tucumán y Salta. Donde había alguien que podía recibirla, ahí iba ella a probar suerte. Cuando las cosas iban bien se

${ }^{17}$ Esta es una expresión de uso corriente con la que las TyT caracterizan su vida después de haber asumido su género femenino. 
quedaba por un tiempo, pero en cuanto empezaban las complicaciones con la policía en la zona de prostitución volvía a partir, porque sabía que eso le podía costar la vida. Contaba, por ejemplo, que a raíz de la muerte de una compañera de la zona ${ }^{18}$ provocada por una fuerte golpiza-, realizó una denuncia que involucraba a altos funcionarios de la fuerzas de seguridad de la provincia de Córdoba, y como consecuencia fue amenazada en reiteradas oportunidades. Eso la llevó a migrar a Tucumán para protegerse. Recién tres años después, cuando todo se calmó, pudo regresar a Córdoba.

Tenemos una vida de aquí y de allá. A veces nos vamos detrás de una promesa, de una ilusión, vamos probando que tal nos va en un lugar y en el otro. Otras, nos vamos escapando (...) Cuando uno no tiene nada, absolutamente nada, nada te ata a ningún lugar. Porque ya no tenés el vínculo familiar, no tenés un trabajo digno, tus amigas son esporádicas porque muchas viajan como vos, a otras las mata la policía, y otras tantas se las lleva el SIDA, entonces, de repente, una te invita, te dice que ahí se trabaja bien, y agarras lo poco que tenés y vas. Así hasta que encontrás lo que realmente te hace bien, lo que te hace vivir más tranquila al menos por un rato. Pero lo nuestro es esa vida de ir y venir. Andamos siempre de paso. Somos como las golondrinas... (Entrevista de la autora a Daniela, Ciudad de Buenos Aires, 12/07/2013).

Distintas fueron las razones que la llevaron a Lola a dejar su casa familiar. Hasta entonces había mantenido su feminidad constreñida a las cuatro paredes de la habitación, porque sospechaba la resistencia por parte de sus padres y los conflictos que esto conllevaría en el seno de la vida familiar. Es por eso que el irse lejos fue la salida que ella encontró para asumirse como travesti.

A los diecisiete años viajó a Buenos Aires en busca de una ilusión: construir y vivir su feminidad como había añorado desde pequeña. Lo hizo en complicidad y acompañada de Mayra, otra chica trans del barrio que también quería viajar a la capital con el propósito de armarse ${ }^{19}$.Convencidas de que no tenían nada que perder y todo por ganar ahorraron algo de dinero trabajando durante el verano y migraron hacia la ciudad prometida, intrépidas a la vez que inexpertas.

El día que llegaron a Retiro ${ }^{20}$ se tomaron un taxi directo al hotel Gondolín ${ }^{21}$ donde una chica con una peluca de trenzas rubia se asomó por el balcón y con un tono irónico y acogedor a la vez les dio la bienvenida en su calidad de novatas. Cuando entraron al hotel había chicas que recién llegaban de la zona roja de Palermo, otras estaban sentadas en la escalera principal conversando y tomando cerveza, y algunas otras se paseaban en ropa interior semi desnudas por los pasillos. El Gondolín fue testigo de su proceso de transformación y del comienzo de su vida vinculada a la prostitución.

\footnotetext{
${ }^{18}$ En la jerga de TyT vinculadas a la prostitución se conoce como "la zona" al lugar donde esperan y se ofrecen a sus clientes.

${ }_{19}$ En la jerga trans se denomina armarse a la práctica de intervenirse el cuerpo ya sea con inyecciones de silicona líquida en diferentes partes del cuerpo (mamas, glúteos, caderas y ocasionalmente en el rostro) o a la operación quirúrgica para colocarse implantes mamarios, por mencionar los procedimientos más comunes.

20 Retiro es la estación de buses más grande de Buenos Aires, donde salen (y llegan) micros hacia las distintas provincias del país.

${ }^{21}$ El Hotel Gondolín es una emblemática pensión donde a partir de la década de los '90 comenzaron a alojarse las travestis y las transexuales que llegaban del resto de las provincias del país a Buenos Aires. Está ubicada en la intersección de las calles Aráoz y Jufré en el barrio porteño de Villa Crespo. Desde el año 2000, luego del fallecimiento de su dueño, es gestionado por un grupo de travestis y transexuales, y años más tarde se convirtió en Asociación Civil Gondolín. Para más información véase http://a.c.gondolin.tripod.com/
} 
Otros fueron los motivos que la llevaron a Carmela a migrar hacia Europa a los 28 años. La esperanza de mejorar sus condiciones de vida y de trabajar en la calle más resguardada del hostigamiento y la violencia policial, que por esos años -década de los '90 en la Argentina- era la segunda causa de muerte entre las TyT.

Después de probar suerte primero en Mar del Plata y luego en Rosario con la prostitución, empezó a considerar la alternativa que habían tomado otras compañeras transexuales. Entre ellas se comentaba que las que habían migrado a Francia estaban trabajando muy bien porque allí la zona roja estaba liberada de la policía. Fue entonces cuando se decidió a ahorrar el dinero necesario para el pasaje de avión y se aventuró hacia la ciudad parisina. Así relataba su experiencia:

\begin{abstract}
Una se va creyendo en el mito de que viajas allá [Europa] y vas a trabajar más protegida y menos expuesta a los peligros con los que te enfrentas en el trabajo en la calle. Y además te vas convencida de que vas a ganar más plata que acá [Argentina] y vas a poder volver con la idea de tener lo tuyo [una casa] para vivir mejor...Pero la verdad es que cuando yo me fui -y eso que recorrí Italia, España y Francia- me costó trabajar...al principio estuve semanas sin hacer un peso...ganaba 10 euros...y además es como en todos lados hay que ganarse la parada [el derecho de piso] Había días que ganabas, otros que no, y otros que perdías todo cuando llegaba la policía y había que negociar lo de la zona. Y agradecer que no te arrastraran por el piso de los pelos o te cagaran a bastonazos. La verdad es que aquella realidad estaba muy inflada...son pocas las que realmente sacan un beneficio, las hay, pero son las menos (Entrevista de la autora a Carmela, Lanús, 12/11/2014).
\end{abstract}

En ese andar "de paso", yendo y viniendo, las TyT van construyendo su género femenino alejadas de las miradas reprobatorias al tiempo que van buscando mejorar sus condiciones de vida. En ese recorrido, entablan fuertes lazos sociales con sus pares, prueban suerte en distintos lugares, y también se desilusionan. $Y$ esas profecías comienzan a presentarse como "destino".

\title{
Aprender el oficio de la prostitución
}

Como vimos en los apartados anteriores, las travestis y las transexuales que tempranamente se han desafiliado de la familia comienzan a transitar por otros espacios -la calle, el hotel y la pensión- donde construyen significativos vínculos de sociabilidad que serán determinantes en sus trayectorias de vida. En ese itinerario, y en los lazos que construyen unas con otras se va transmitiendo e incorporando la idea de obtener dinero para vivir con aquello que tienen a su alcance: su cuerpo. De esta manera, el universo relacional de las TyT termina coincidiendo con el mundo de la prostitución callejera.

Vanesa es cordobesa, tiene 27 años, y vive en la Ciudad de Buenos Aires. Se inició en la prostitución cuando tenía quince. Fue Malena, una mujer transexual varios años más grande que ella y de su mismo barrio quien la convenció de que siendo travesti de lo único que podía vivir era de la calle. Y así fue como la llevó por primera vez a la parada ${ }^{22}$ y le transmitió su saber hacer en la prostitución. Gracias a ella, Vanesa aprendió cómo pararse en la esquina, qué ropa vestir, los códigos de convivencia con las otras chicas (de la parada), cómo negociar con los clientes y de qué manera protegerse para no sufrir abusos sexuales ni situaciones de violencia.

\footnotetext{
${ }^{22}$ Se denomina "parada" a la zona de prostitución.
} 
La primera noche que fueron juntas a la zona de prostitución, Vanesa observó a Malena interactuar con los clientes durante algunas horas hasta que, por fin, se animó a responder a la demanda de uno de ellos. Lo recuerda como un momento difícil, "de esos que te marcan". Pero después con el correr del tiempo se fue acostumbrando ya que se había convencido que "no le quedaba otra".

De manera similar Zoe empezó a "hacer la calle"23. Cuando llegó de su Mendoza natal a Buenos Aires con trece años, y se instaló en Moreno, conoció a Beatriz, una "travesti vieja" de 34 años $^{24}$ que tenía algunos clientes fijos en la parada de la ruta. Le dijo que como era bonita tenía futuro. Pero le advirtió que tenía que armarse porque si no los clientes se van con otras.

En ese gesto se pone de manifiesto cómo el ejercicio de la prostitución incide sobre la construcción de sus cuerpos, ya que "existen expectativas sociales respecto a cómo debe ser el cuerpo de la travesti por parte de la sociedad en general" (Zambrini, 2008: 134). La producción de sus cuerpos está atravesada por la tensión entre los propios deseos y los condicionantes del consumo prostibular (Berkins y Fernández, 2005:81).

En el caso de Zoe fue una amiga que conoció en la ruta quien le aplicó inyecciones de silicona industrial en los pechos, las caderas y la cola. "Me acosté sobre una mesa de madera boca arriba durante largo tiempo, y ella de a poco me fue colocando con una aguja de veterinaria la silicona, mientras que otra chica me sostenía de los brazos para que no me moviera, porque del dolor que sentía cada tanto pegaba algún alarido".

De acuerdo a lo que muestran los estudios existentes referenciados al comienzo de este artículo la gran mayoría de las travestis y transexuales se aplica en su cuerpo siliconas sin recurrir a una institución médica. Lo hacen de manera casera a través de amigas o conocidas "con algo de experiencia" y en lugares que no poseen las condiciones de asepsia necesarias para llevar adelante ese procedimiento. Cuando se indaga el motivo por el cual no concurren a los hospitales o a algún especialista, ellas responden que es por temor a la burla y a la discriminación. Lo preocupante de esta situación es que después del VIH-SIDA y los asesinatos (conocidos como crímenes de odio), las complicaciones derivadas de procedimientos de inyección de siliconas en condiciones de precariedad es otra de las principales causa de deceso para las TyT.

Paralelamente a la aplicación de siliconas, Zoe acompañó a Beatriz a la ruta religiosamente de jueves a domingos. Ella le enseñó los gajes del oficio y sobre todo a cuidarse de la policía y qué hacer cuando se la llevaran detenida. Y si bien Zoe tiene recuerdos encontrados de esa época, porque considera que a partir del momento en que asumió su identidad trans se produjo una "interrupción de su niñez", reconoce que Beatriz fue como esa madre que había perdido, ya que la protegió en un momento de mucho desamparo. Así rememora su comienzo en la prostitución:

La verdad es que yo seguía muy enojada con todo lo que me había pasado, salir huyendo de mi casa, dejar todo, no tener nada. Nunca quise pararme en la calle, tener que prostituirme...Yo sabía que de alguna manera me estaban arrebatando mi vida de chica, y el comienzo de mi adolescencia. Porque yo tenía que estar estudiando en la escuela, o yendo a algún recital como tantos otros chicos y chicas de mi edad, o en mi casa con mi familia. Y no un viernes a la noche estar parada en la zona y cagada de frío...La verdad es que me daba mucha impotencia... Pero bueno, había que comer, que vestirse, que pagar la pensión.

\footnotetext{
${ }^{23}$ En la jerga trans se denomina "hacer la calle" a la práctica de prostituirse.

${ }^{24}$ Se la identifica como una "travesti vieja" dado que la expectativa de vida hasta hace pocos años era, como mencionamos anteriormente, de 35 años.
} 
¿Y qué otra cosa iba a hacer una trava más que prostituirse? (Entrevista de la autora a Zoe, Moreno, Provincia de Buenos Aires, 23/07/2013)

En el relato de Zoe comienza a delinearse la autoprofecía cumplida de las TyT. Ante el desamparo y la necesidad de ganarse la vida, la prostitución se erige como una alternativa "inevitable".

Volviendo a Daniela, cuando llegó a la Pajarera aún no se había iniciado en la prostitución. En la pensión conoció a Sabrina y a Eleonora, con quién le tocó compartir la pieza que alquilaba. Las dos vivían "de la calle" desde hacía un par de años atrás. Y también se habían ido expulsadas de su casa familiar como consecuencia de la incomodidad que provocaba su expresión de género.

Durante los primeros tiempos en la Pajarera, Daniela vivió con el dinero de la indemnización. Aunque sus compañeras trataban de persuadirla de que lo usara para armarse y saliera con ellas a hacer la calle. Ella sabía que su transformación no tenía vuelta. Y ya no podía volver a intentar conseguir un empleo camuflado de hombre. Así que cuando se quedó sin dinero se puso la minifalda, los tacos y se fue a parar a la esquina con las chicas. Así lo rememora:

\begin{abstract}
Cuando se me acabó la indemnización, no la pasé nada bien: no tenía para comer, ni para pagar la pensión donde me alojaba, no tenía para moverme...y eso es lo que te condiciona, la situación, la sociedad te condiciona y te lleva a eso: sos trava, bueno, entonces a pararse a la esquina y de noche, y bien allá, lejitos, a donde nadie te vea. ¿De qué otra manera vas a vivir y con qué vas a mantenerte que no sea con la prostitución? (Entrevista de la autora a Daniela, Cdad. de Buenos Aires, 13/7/2013).
\end{abstract}

A partir de los relatos recogidos, podemos observar cómo esa representación que postula a la prostitución como única alternativa para obtener dinero circula con pregnancia entre las mismas TyT. Ante esta situación de supuesta inevitabilidad, las travestis que tienen más experiencia en la calle son quienes introducen a las más jóvenes en lo que saben hacer para ganarse la vida: prostituirse. Se produce así una especie de "socialización anticipante" (Goffman, 1981: 40) donde las más experimentadas comparten y despliegan con las novatas un repertorio de sugerencias, consejos, performances y códigos de convivencia, con la intención de brindarles herramientas que las ayuden a desenvolverse en la calle.

Pero no sólo eso. Durante mi trabajo de campo escuché en reiteradas oportunidades que TyT, cuyas trayectorias de vida se vinculan a la prostitución desde pequeñas, se referían a otras travestis de mayor edad -aunque no necesariamente con tantos años de diferencia- como "mi madraza". Dado que muchas de las aprendices son adolescentes o incluso pre-adolescentes, las travestis de mayor edad entablan con ellas, también, un vínculo de cuidado y protección, es decir, desarrollan una suerte de rol maternal con las travestis que se van sumando a su grupo de convivencia o parada callejera de la transprostitución (Álvarez Broz, 2017).

A este tipo de vínculo, que incluye tanto el transmitir los avatares de la transprostitución como la construcción de un vínculo afectivo entre las más jóvenes y las travestis más grandes, Fernández (2004) lo denomina una relación de pupilaje, en tanto implica acompañar el desarrollo psico-social como tutorear su práctica callejera con los clientes. 


\section{Comentarios finales}

Tal como mostré hasta aquí, una vez que las TyT abandonan sus hogares y se desafilian de sus familias "de origen" inician un itinerario donde, indefectiblemente, tienen que aprender a "arreglárselas solas". En ese recorrido circulan por espacios como la calle, el hotel y la pensión donde se encuentran con otras TyT y se reconocen en 'su diferencia'. Esa diferencia, que es constitutiva de sus procesos de subjetivación trans, las conduce a construir fuertes lazos de solidaridad y fraternidad sumamente significativos y determinantes para el curso de sus vidas. En el tejido de esas redes sociales potenciarán sus recursos y capacidades contribuyendo a mejorar sus condiciones de vida en varios aspectos.

En primer lugar, es en el marco de esa familia "entre pares" que ellas comparten saberes "prácticos" cuando se montan o se trucan las partes íntimas de su cuerpo con el propósito de disimular sus rasgos masculinos al tiempo que exaltar los femeninos. Del mismo modo, cuando llevan adelante prácticas de intervención corporal -eludiendo al sistema de salud legal y público- realizadas por ellas mismas y con la ayuda de sus compañeras y, por tanto, consideradas colectivas (Rugna, 2015).

En segundo lugar, es entre compañeras que llevan adelante un proceso de socialización anticipante donde van aprendiendo los códigos de la supervivencia callejera como así también las habilidades necesarias para moverse en el ambiente de la transprostitución. Como expuse oportunamente, mediante una relación de pupilaje (Fernández, 2004) las TyT de mayor experiencia no sólo introducen sino también les transmiten a las novatas el metié de la transprostitución y las maneras de vincularse y, eventualmente, protegerse de los clientes. Es a partir de esta socialización anticipante -que incorporan a partir del vínculo con sus pares- que desarrollan tácticas (De Certeau, 1996) para ganarse la vida y satisfacer sus necesidades básicas cotidianas.

En tercer lugar, es también entre ellas que desarrollan redes de asistencia y contención. Por ejemplo, cuando ante la negación de acudir a una institución médica por temor a ser estigmatizadas y maltratadas -tal como señalan los datos estadísticos- se acompañan y se cuidan entre sí al momento de caer enfermas y se sostienen económicamente en aquellas oportunidades en que no recaudaron lo suficiente durante la noche para cubrir los gastos de la habitación que alquilan o ante la necesidad de comprar remedios.

Estos intercambios y redes de ayuda constituyen, a mi entender, un verdadero pacto entre feminidades que podemos analizar y comprender a la luz de lo que se conoce como sororidad. Esta es una forma de relacionamiento particular y específica entre mujeres -que hago extensiva a las TyT-con el propósito de conformar una alianza existencial y política, cuerpo a cuerpo, subjetividad a subjetividad, tendiente a lograr reconocimiento, apoyo mutuo, transmisión de saberes y descubrimientos (Lagarde, 1989) que inciden favorablemente en su calidad de vida.

De este modo, frente al desamparo y la desprotección que experimentan las TyT por la falta de la familia nuclear, sumado a la temprana edad en la que asumen su identidad de género, se reconocen y se hermanan con otras como ellas, construyendo un fuerte vínculo de fraternidad que se va tramando ante la necesidad y la urgencia de acompañamiento, resguardo y reconocimiento.

Estas modalidades de armar redes de solidaridad y de desarrollar mecanismos de reciprocidad contribuye a comprender cómo, ante ciertas adversidades que se les presentan a las personas trans, específicamente a las TyT, son capaces de crear lazos sociales y nutrirse de recursos para hacer frente a los episodios de discriminación y para transitar y sobrellevar situaciones de desventaja social. $Y$ si bien estas prácticas y 
mecanismos no impiden la generación de inequidades sociales, no por ello dejan de tener un potencial fundamental, puesto que la desigualdad sería, sin duda, mucho mayor si no existieran (Reygadas, 2008).

El estudio de las trayectorias de travestis y transexuales vinculadas a la prostitución me permitió reflexionar en torno de los modos en cómo se va tramando una identidad de género disidente con las consecuencias desigualadoras que acarrea dicho proceso. Sin perder de vista que el juntarse con otras TyT les permite sobrellevar y hasta atemperar esas condiciones de desventaja social que se van combinando y potenciando a lo largo de sus itinerarios biográficos.

Esto me permite decir que las distintas tácticas y modalidades de acción que desarrollan las TyT constituye un aporte más al conocimiento sobre cómo se articula la diferencia sexo-genérica con experiencias y procesos de desigualdad social pero también con la capacidad para llevar adelante prácticas para transformarlas. Sin desestimar, claro, la paradoja que se les presenta: las redes sociales que construyen les proporcionan una red de contención y apoyo al mismo tiempo que coadyuvan a la reproducción de prácticas de riesgo y exclusión social.

\section{Bibliografía}

Alonso, I. (1998). La mirada cualitativa en sociología: una aproximación interpretativa. Madrid: Fundamentos.

Álvarez Broz, M. (2017). ¿Cuánta (des)igualdad somo capaces de aceptar? Formas, mecanismos y relaciones de (des)igualdad en las personas trans de la Argentina contemporánea (1990-2015). San Martín: Tesis de Doctorado en Sociología, Instituto de Altos Estudios Sociales y Universidad Nacional General de San Martín.

Berkins, L. (2003). Un itinerario politico del travestismo. En D. Maffia, Sexualidades migrantes. Género y Transgénero (págs. 127-137). Buenos Aires: Feminaria.

Berkins, L. y Fernández, J (2005). La gesta del nombre propio. Buenos Aires: Madres de Plaza de Mayo.

Berkins, L. (2007). Informe Nacional sobre la situación de las travestis, transexuales y transgéneros. Cumbia, copeteo y lágrimas. Buenos Aires: Asociación de Lucha por la Identidad Travesti-Transexual.

Bertaux, D (ed) (1981). Biography and Society. The Life-History approach. Lodres: Sage. 1999). El enfoque biográfico: su validez metodológica, sus potencialidades. Proposiciones, 29, 1-22.

Bellaterra.

(2005). Los relatos de vida. Perspectiva etnosociológica. Barcelona:

Boletín Epidemiológico VIH-sida (2009). Boletín sobre VIH-Sida en la Argentina №26. Noviembre de 2009: Ministerio de Salud de la Nación.

Bourdieu, P. (1977). La ilusión biográfica. Razones prácticas. España: Anagrama.

Cutuli, M. (2013). Maricas y travestis: repensando experiencias compartidas. Sociedad y Economía, 183-204. 
De Certeau, M. ([1990] 1996). La invención de lo cotidiano. Artes de hacer. Mexico DF: Universidad lberoamericana.

Douglas, M. (2004). Risk and Blame. Essays in Cultural Theory. Nueva York: Routledge.

Defensoría de la ciudad de Buenos Aires (1999). Informe preliminar sobre la situación de las travestis de la Ciudad de Buenos Aires. Buenos Aires.

Farji Neer, A. (2016). Sentidos en disputa sobre los cuerpos trans: los discursos médicos, judiciales, activistas y parlamentarios en Argentina entre 1966-2015. Buenos Aires: Tesis de doctorado, Facultad de Ciencias Sociales, Universidad de Buenos Aires.

Fernández, J. (2004). Cuerpos desobedientes. Travestismo e identidad de género. Buenos Aires: Edhasa.

Fraser, $N$ (1995). ¿From redistribution to recognition? Dilemmas of Justice in a 'Postsocialist' Age. New Left Review, 212, pp. 68-93.

Fundación Huésped (2012). Informe Ejecutivo sobre Percepciones y experiencias sobre estigma y discriminación en poblaciones trans, HSH y usuarios de drogas. Fundación Huésped: Buenos Aires.

Goffman, E. ([1963] 2012). Estigma. La identidad deteriorada. Buenos Aires: Amorrortu. Amorrortu.

(1981). La presentación de la persona en la vida cotidiana. Buenos Aires:

INDEC e INADI (2012). Informe de la Prueba Piloto de la Encuesta sobre Población Trans: travestis, transexuales, transgéneros y hombres trans. Buenos Aires: Dirección Nacional de Estadisticas Sociales y de Población, Instituto Nacional de Estadística y Censo (INDEC) e Instituto Nacional contra la Discriminación, la Xenofobia y el Racismo (INADI).

Jones, D., Libson, M. y Hiller, R. (2006). Sexualidades, política y violencia. La marcha del Orgullo GLTTBI Buenos Aires 2005. Segunda Encuesta. Buenos Aires: Grupo de Estudios sobre Sexualidades. Editorial Antropofagia.

Kessler, G. (2004). Sociología del delito amateur. Buenos Aires: PAIDOS.

(2014). Controversias sobre la desigualdad. Argentina 2003-2013. Buenos Aires: Fondo de Cultura Económica.

Kornblit. (2007). Historias y relatos de vida: una herramienta clave en metodologías cualitativas. En A. L. Kornblit, Metodologías cualitativas en Ciencias Sociales. Modelos y procedimientos de análisis. (págs. 15-31). Buenos Aires: Biblos.

Marradi, A. (2012). La entrevista en profundidad. En A. Marradi, N. Archenti, \& J. Piovani, Metodología de las Ciencias Sociales (págs. 191-197). Buenos Aires: Cengage Learning Argentina.

Meccia, E., Metlika, U., y Raffo, M. (2001). Callejear los márgenes. Presentación de algunas conjeturas sociológicas para el análisis del trabajo sexual en el Conurbano Bonaerense. Buenos Aires: Facultad de Ciencias Sociales, Universidad de Buenos Aires.

Meccia, E (2011). Los últimos homosexuales. Buenos Aires: Gran Aldea. 
Míguez, D. (2010). Los Pibes chorros. Estigma y marginación. Buenos Aires: Capital intelectual.

Ministerio de Salud de la Ciudad (2005). Encuesta Nacional de Factores de Riesgo 2005. Informe de resultados (versión breve). Buenos Aires: Ministerio de Salud de la Nación.

Ministerio de Salud de la Nación (2010). Las experiencias de atención médica y los cuidados del cuerpo en personas travestis/trans. Condiciones de vulnerabilidad al VIHSIDA e ITS y problemas de acceso a la atención de la salud en personas homosexuales, bisexuales y trans en la Argentina. Buenos Aires: Dirección de Sida y ETS, Ministerio de Salud de la Nación Argentina, 2010.

Lagarde, M. (1989). Enemistad y sororidad: hacia una nueva cultura feminista. Memoria del Cemos Vol. IV №28.

Pecheny, M. (2001). Ciudadanía y minorías sexuales. Buenos Aires: Universidad de Buenos Aires.

Petracci, M. y Pecheny, M. (2006) Sexualidad y derechos humanos humanos. Informe Final presentado al Centro Latinoamericano de Sexualidad y Derechos Humanos: CLAM.

Pecheny, M y De La Dehesa, R (2011). Sexualidades y políticas en América Latina: un esbozo para la discusión. Río de Janeiro: SPW.

Plummer, K (1994). Telling Sexual Stories: Power, Change, and Social Worlds, Routledge.

Prieur, A. (1998). Mema's house, México City. On travestites, queens and machos. Chicago: Chicago Press.

Pollak, M. (1993). Une identité blessée. Etudes de sociologie et d'histoire . Paris: Métailié.

Reygadas, L. (2008). La apropiacion. Destejiendo las redes de la desigualdad. México: Antrophos.

Rubin, G. (1989). "Reflexionando sobre el sexo: notas para una teoría radical de la sexualidad". En C. Vance, Placer y peligro. Explorando la sexualidad femenina (págs. 113-190). Madrid: Revolución.

Rugna, C (2015) Las prácticas de intervención corporal de los movimientos sociosexuales frente al sistema experto de salud (legitimado para decir y hacer sobre los sujetos-cuerpos), XI Jornadas de Sociología. Facultad de Ciencias Sociales, Universidad de Buenos Aires.

Zambrini, L. (2008). Cuerpos, indumentarias e identidades de géneros. En M. Pecheny, C. Flgari, \& D. Jones, Todo sexo es político. Estudios sobre sexualidades en Argentina (págs. 123-146). Buenos Aires: Libros del Zorzal. 